\title{
A comparative study of attitudes towards psychiatry among final year undergraduate, interns and postgraduate medical students in a medical college in India
}

\author{
Manik Changoji Bhise ${ }^{1}$, Angad Singh Kochar ${ }^{2}$ \\ ${ }^{1}$ Professor and Head, Department of Psychiatry, MGMs Medical College, Aurungabad. \\ ${ }^{2}$ Consultant Psychiatrist, Private Practice, Delhi. \\ Corresponding Author: Manik Bhise \\ Email: dr.manik.bhise@gmail.com
}

\begin{abstract}
Background: Attitudes towards psychiatry is shaped by various factors, of which training in subject is often reported as most important influence in shaping it. The available literature is mixed with some studies reporting improvement and some reporting negative attitude after training in psychiatry. The objective of the present study was to compare the attitude towards psychiatry on ATP 30 scale among undergraduate students, interns and postgraduate students and to assess association between self-reported attendance during undergraduate training and attitude towards psychiatry.

Methodology: Cross sectional study design was used to collect data from 100 participants in each group of final year MBBS students, Interns who had completed psychiatry posting and postgraduate students from other departments. Attitude towards psychiatry was assessed using ATP-30 Questionnaire. Students self reported their percentage of attendance during undergraduate training.

Results: Overall Mean total score for ATP-30 revealed positive attitude toward s psychiatry among all three groups, with significant high scores among postgraduate students compared to undergraduates. Compared to undergraduates and interns, significantly fewer postgraduate students had negative attitude. Negative attitude was significantly associated with reported absenteeism during undergraduate psychiatry training.

Conclusion: As students progressed in their medical curriculum, attitude seems to improve with more training and exposure to patients and subject per say.
\end{abstract}

Key Words: Attitude, psychiatry, Indian medical graduate, Psychiatry curriculum.

(Paper received $-30^{\text {th }}$ April 2020, Peer review completed $-6^{\text {th }}$ June 2020)

(Accepted $-7^{\text {th }}$ June 2020)

\section{INTRODUCTION}

Psychiatry training in undergraduate medical curriculum is important in shaping knowledge and attitude of medical students toward subject. There has been emphasis on increasing duration of psychiatry training in curriculum as well as emphasis on making it a separate subject with compulsory exam paper and not just part of internal medicine [1]. However prior studies from west as well as India have revealed that majority of students harbour negative attitude towards psychiatry as subject, psychiatric patients and psychiatrists themselves [2-3]. Studies also suggest that as exposure to psychiatry and medical education per say increases, attitude of students gradually changes towards positive side but this varies as per intensity of training and interest shown by students [4-6]. Indian medical graduate (IMG) during their undergraduate training have 22 didactic lectures and 15 day of clinical posting, however this is as a part of internal medicine and allied subject and there is no separate subject exam to be passed before becoming graduate. With the new competency based curriculum of MCI being implemented, students will be having chance to opt for optional posting in subject as well as will have to learn defined competencies systematically [7]. However, this new curriculum doesn't require IMG to demonstrate any skill in psychiatry as compulsion to become a 
medical graduate, and this has been criticised widely [8]. With this situation of medical education in India present study was done to compare the attitude towards psychiatry on ATP 30 scale among undergraduate students, interns and postgraduate students and to assess association between self-reported attendance during undergraduate training and attitude towards psychiatry.

\section{METHODOLOGY}

The study was conducted in psychiatry department of medical college in western India, with intake capacity of 150 undergraduate medical students (MBBS), internship program in place and nearly 152 postgraduate medical students. A cross sectional study design was used to collect data. Study was conducted in one month period of February 2016, when most interns have completed their compulsory rotatory psychiatry posting of 15 days. A prior Institutional ethic committee approval was obtained

\section{Sample}

The study Participants belonged to three groups: 100 final year MBBS students who have completed their 22 didactic lectures and 15 days clinical posting in psychiatry; 100 interns who have completed their compulsory rotatory internship posting of 15 days; and 100 post graduate students working in non-psychiatry department. All participants were approached by researchers for voluntary participation and were included in the study after written informed consent. Any participant with prior psychiatric illness history or ongoing treatment for psychiatric illness was excluded from study.

\section{Assessment}

All the participants were assessed with the predesigned and pretested questionnaire to record sociodemographic variables. Attitude towards psychiatry-30 (ATP- 30) questionnaire was used to assess attitude of all three groups towards psychiatry [9]. This questionnaire with 30 items assesses following eight dimensions of attitude towards: (1) psychiatric patients, (2) psychiatric illness, (3) psychiatrists, (4) psychiatric knowledge, (5) psychiatry as a career choice, (6) psychiatric treatment, (7) psychiatric institutions and (8) psychiatric teaching respectively using various combination of questions. Advantage of this questionnaire is that it has a combination of both positively and negatively phrased statements which reduces responder's bias. It is scored in the Likert format of 5 options ranging from 1 - strongly agree to 5 - strongly disagree. Before entering data into excel sheet, positively phrased items (numbers 4, 5, 9-12, 14, 15, 18, 20 , 23,25 , and 27-29) are reversed by subtracting the score from 6 . Total score is calculated by sum of all the responses. It has a maximum score of 150 . Prior studies in medical students considered ATP- 30 total score of 90 as neutral, score of $<90$ as suggesting negative attitude, and score above 90 shows positive ATP. ATP30 questionnaire has high face, concurrent, and construct validity with split- half reliability comparable to most of the attitudinal scales [10]. In addition to ATP-30 questionnaire two additional questions were included to self report how much percentage of theory and clinical psychiatry training was attended by students during their under graduation. This was self reported and there was no pressure on MBBS students as their attendance has already been finalised and submitted to university from internal medicine department.

\section{STATISTICAL ANALYSIS}

For class variables, Chi- square test was used. For continuous variables, descriptive statistics (mean, percentages) was calculated to analyse the characteristics of participants. One way ANNOVA was used to compare variables amongst three groups and Turkey's HSD Post hock analysis was done to find out the significance within the groups. Significance for $P$ value was set at $<0.05$. 


\section{RESULTS}

Data was collected from 100 students in each of three groups. Mean age (in years) of undergraduate medical students was $21.7(\mathrm{SD}=0.5)$, Interns $24.1(\mathrm{SD}=1.5)$, post graduate students $26.5(\mathrm{SD}=1.8)$, mean variation in age was significant $(p=0.01)$. There was no significant difference among three groups in terms of sex $\left(X^{2}\right.$ $=2.0, \mathrm{df}=2, \mathrm{p}=0.3)$.

Mean ATP- 30 score of undergraduate medical students was 94.37 (SD = 11.7), interns 94.55 (SD=11.8) and that of postgraduate students was $116.18(\mathrm{SD}=15.9)$; indicating overall all three groups had positive attitude towards psychiatry, however as exposure to psychiatry training in particular (up to internship) and training in medical field in general progressed this attitude improved significantly with higher scores in postgraduate students $(\mathrm{F}=88.6, \mathrm{df}=2, P=0.01)$. Based on a neutral score of 90 , students were grouped into those with total score $<90$ (negative ATP) and those with total score more than 90 (positive ATP). Among three groups, negative attitude towards psychiatry was found in $36.6 \%$ under graduate medical students, $44.90 \%$ interns and only $5.05 \%$ postgraduate students, indicating significant improvement in attitude as students were getting more medical training and experience during education. There was no difference in positive or negative attitude among tow sexes $\left(\mathrm{X}^{2}=1.4, \mathrm{P}=0.7\right)$.

Analysis of mean scores across eight different domains of ATP-30 reveals that all three groups had positive attitude towards psychiatric patients and psychiatric illness with significantly higher mean scores for postgraduate students (Table-1). Attitude towards psychiatrist seems more pessimistic for what psychiatrists can do for their patient and work satisfaction they get compared to other specialities. Undergraduate students had negative attitude about scientific knowledge base of psychiatry as a speciality, psychiatric treatments causing worries in patients, psychiatry training being amorphous and not being useful to understand other specialities better. Turkey's HSD Post hock analysis for most of these questions revealed that there was significant intergroup difference between undergraduate students and post graduate students, while only for few questions interns and postgraduate students differed. All three groups harboured significant negative attitude towards psychiatry as carrier choice where of five questions, all three groups had similar negative attitude on three questions i.e. 'I would like to be a psychiatrist', 'psychiatry will be excluded from top three speciality list' and 'psychiatry trainees are running away from real medicine'.

We analysed association between self-reported attendance and over all attitude of students towards psychiatry. Overall, only $36.33 \%$ students had reported to attend more than fifty percent of theory classes. Those who attended less than fifty percent of theory classes, $31.94 \%$ harboured negative attitude towered psychiatry while among those who attended more than fifty percent of theory classes only $19.27 \%$ harboured negative attitude $\left(X^{2}=5,6, p=0.008\right)$. Similarly, only $36.67 \%$ students reported to have attended more than fifty percent practical/ clinics during undergraduate training. Here also those who attended less than fifty percent of clinics, $31.58 \%$ harboured negative attitude towards psychiatry while among those who attended more than fifty percent of theory classes only $20.00 \%$ harboured negative attitude $\left(X^{2}=4,7, p=0.01\right)$.

Table 1: Mean score for different domains of attitude in ATP 30 Questionnaire among three groups of medical students

\begin{tabular}{|c|c|c|c|c|c|c|}
\hline $\begin{array}{l}\text { Attitude } \\
\text { Domains }\end{array}$ & Statements * & $\begin{array}{l}\text { Final } \\
\text { year } \\
\text { MBBS }\end{array}$ & Interns & $\begin{array}{l}\text { Post } \\
\text { graduate }\end{array}$ & F stat & $\begin{array}{l}\mathbf{P} \\
\text { value }\end{array}$ \\
\hline \multirow{2}{*}{$\begin{array}{l}\text { Psychiatric } \\
\text { patients }\end{array}$} & If we listen to them, psychiatric patients are just as human as other people & 3.64 & 3.38 & 4.32 & 22.11 & $<0.01$ \\
\hline & Psychiatric patients are often more interesting to work with than other patients & 3.39 & 3.17 & 3.92 & 12.42 & $<0.01$ \\
\hline \multirow{2}{*}{$\begin{array}{l}\text { Psychiatric } \\
\text { illness }\end{array}$} & Psychiatric illness deserves at least as much attention as physical illness. & 3.73 & 3.45 & 4.48 & 24.38 & 0.02 \\
\hline & It is interesting to try to unravel the cause of a psychiatric illness & 3.73 & 3.15 & 4.17 & 21.6 & $<0.01$ \\
\hline \multirow[t]{6}{*}{ Psychiatrists } & Psychiatrists talk a lot but do very little & 3.02 & 3.14 & 4.3 & 44.04 & $<0.01$ \\
\hline & Psychiatrists seem to talk about nothing but sex. & 3.23 & 3.34 & 4.35 & 27.54 & $<0.01$ \\
\hline & Psychiatrists tend to be at least as stable as the average doctor & 3.31 & 3.06 & 4.15 & 25.7 & $<0.01$ \\
\hline & Psychiatrists get less satisfaction from their work than other specialists & 2.70 & 3.32 & 3.32 & 9.09 & 0.06 \\
\hline & There is very little that psychiatrists can do for their patients & 3.17 & 3.17 & 3.15 & 0.08 & 0.9 \\
\hline & At times it is hard to think of psychiatrists as equal to other doctors & 3.00 & 3.41 & 3.77 & 12.11 & $<0.01$ \\
\hline \multirow{2}{*}{$\begin{array}{l}\text { Psychiatric } \\
\text { Knowledge }\end{array}$} & Psychiatry is a respected branch of medicine & 3.2 & 3.2 & 4.1 & 21.31 & 0.03 \\
\hline & Psychiatry has very little scientific information to go on & 2.94 & 3.14 & 3.49 & 6.20 & 0.01 \\
\hline
\end{tabular}




\begin{tabular}{|c|c|c|c|c|c|c|}
\hline & $\begin{array}{l}\text { Psychiatry is so unscientific that even psychiatrists can't agree as to what its } \\
\text { basic applied sciences are }\end{array}$ & 2.96 & 3.21 & 3.79 & 14.13 & 0.06 \\
\hline & Most of the so-called facts in psychiatry are really just vague speculations & 2.67 & 3.21 & 3.66 & 19.76 & 0.03 \\
\hline \multirow{5}{*}{$\begin{array}{l}\text { Psychiatric } \\
\text { treatments }\end{array}$} & It is quite easy for me to accept the efficacy of psychotherapy. & 3.15 & 3.17 & 3.76 & 11.32 & 0.06 \\
\hline & $\begin{array}{l}\text { The practice of psychotherapy basically is fraudulent since there is no strong } \\
\text { evidence that it is effective } 8\end{array}$ & 3.29 & 3.17 & 3.97 & 14.71 & 0.07 \\
\hline & With the forms of therapy now at hand most psychiatric patients improve & 3.64 & 3.06 & 4.35 & 40.32 & $<0.001$ \\
\hline & Psychiatric treatment causes patients to worry too much about their symptoms & 2.44 & 3.20 & 3.33 & 16.19 & 0.04 \\
\hline & In recent years psychiatric treatment has become quite effective & 3.71 & 3.24 & 4.34 & 30.64 & $<0.01$ \\
\hline \multirow{5}{*}{$\begin{array}{l}\text { Psychiatry as } \\
\text { career choice }\end{array}$} & Psychiatry is unappealing because it makes so little use of medical training & 3.09 & 2.87 & 4.24 & 37.76 & $<0.01$ \\
\hline & I would like to be a psychiatrist & 2.22 & 2.91 & 2.91 & 9.6 & 0.09 \\
\hline & $\begin{array}{l}\text { If I were asked what I considered to be the three most exciting medical } \\
\text { specialties, psychiatry would be excluded }\end{array}$ & 2.75 & 3.05 & 3.02 & 1.85 & 0.1 \\
\hline & $\begin{array}{l}\text { The practice of psychiatry allows the development of really rewarding } \\
\text { relationships with people }\end{array}$ & 3.78 & 3.24 & 4.45 & 43.97 & $<0.01$ \\
\hline & $\begin{array}{l}\text { On the whole people taking up psychiatric training are running away from } \\
\text { participation in real medicine }\end{array}$ & 2.84 & 3.14 & 3.64 & 11.42 & 0.08 \\
\hline \multirow{2}{*}{$\begin{array}{l}\text { Psychiatric } \\
\text { institutions }\end{array}$} & Psychiatric hospitals are little more than prisons & 3.16 & 3.24 & 4.09 & 32.91 & $<0.01$ \\
\hline & $\begin{array}{l}\text { Psychiatric hospitals have a specific contribution to make to the treatment of } \\
\text { the mentally ill }\end{array}$ & 3.68 & 2.88 & 4.12 & 36.35 & $<0.01$ \\
\hline \multirow[t]{4}{*}{$\begin{array}{l}\text { Psychiatry } \\
\text { teaching }\end{array}$} & $\begin{array}{l}\text { The majority of students report that their psychiatric undergraduate training } \\
\text { has been valuable }\end{array}$ & 2.62 & 2.89 & 3.94 & 35.31 & $<0.01$ \\
\hline & $\begin{array}{l}\text { These days psychiatry is the most important part of the curriculum in medical } \\
\text { schools }\end{array}$ & 3.36 & 2.92 & 3.68 & 10.39 & 0.04 \\
\hline & Psychiatry is so amorphous that it cannot really be taught effectively & 2.88 & 3.02 & 3.24 & 2.45 & 0.08 \\
\hline & $\begin{array}{l}\text { Psychiatric teaching increases our understanding of medical and surgical } \\
\text { patients }\end{array}$ & 2.99 & 3.11 & 4.11 & 32.59 & $<0.01$ \\
\hline
\end{tabular}

\section{DISCUSSION}

Attitude towards psychiatry is dynamic and changes as per the exposure to subject and medical education in general. Attitude towards psychiatry is also affected by strong negative socializing pressure from peer, family members and other non-psychiatry faculties as well which discourages student's interest in psychiatry [11]. Present study reveals that the attitude of medical students improved as they were exposed more and more to psychiatry training in MBBS, internship in particular and as they started seeing patients in their respective branches during their post-graduation. However few studies have reported contradictory findings that attitude of medical students became negative towards psychiatry after completing psychiatry training compared to those who did not receive training [11-13]. These studies also expressed valid concerns faced by universities in Africa and Nepal in recruiting postgraduate students for psychiatry training as many students had concerns about social status of psychiatrist, stigma in society and perception of psychiatry practice as less rewarding compared to other medical subjects. Similar findings were replicated in present study where students were pessimistic about doing carrier in psychiatry. Another worrying finding is students doubting scientific knowledge base of psychiatry. This is often replicated finding from prior studies as well [13-14]. This indicates that as medical teachers we need to focus more on teaching latest scientific evidence from genetics, molecular biology and functional imaging and emphasize psychiatric illnesses as disorders of brain and not just mind. India with 1.3 billion population can't rely only on about 10000 psychiatrists to care of its mental health needs. All Indian Medical Graduates need to be equipped with necessary skills to identify and treat psychiatric illnesses at grass root level, and refer to specialist care whenever they can't manage it [1]. From students' part, poor attendance of both theory and clinics in psychiatry is worrying factor for medical teachers. Almost $65 \%$ participants in present study have attended less than $50 \%$ of their psychiatry training in under graduation! This is often reported finding in prior studies which is significantly associated with negative attitude of students $[1,13]$. Various reasons reported for poor attendance are psychiatry being part of internal medicine where attendance gets diluted with large number of theory and clinic in internal medicine and allied subjects; there are no compulsory minimum attendance criteria for psychiatry and allied subjects in general, making students ignore it. Most importantly there is no separate exam in subject and only few short notes are asked as part of paper II on Internal Medicine in final year, where students often have choice to leave that question. This has often been protested by Indian psychiatric Society at various forums and Medical Council of India / National Medical Commission and there have been persistent requests to make psychiatry as separate exam subject with mandatory attendance 
criteria. It is interesting to see that allied health sciences like nursing, physiotherapy have psychiatry and psychology as separate subjects with exam and attendance criteria, but our Indian Medical Graduate do not need to go through it [1].

\section{CONCLUSIONS}

Attitude of medical students towards psychiatry as subject, psychiatric patients, treatments and psychiatry training per say seems to improve with progression of their medical curriculum towards post-graduation. There is urgent need to take actions to impart scientific knowledge base of psychiatry to undergraduate students, incorporate interesting teaching learning methods to engage them and improve attendance and to highlight positive aspects of psychiatry as a carrier choice. This can be achieved by training of medical teachers in Medical Education Technology (MEU) which is compulsory as per Medical Council of India, as well as by mentoring programs run by colleges and universities.

Findings of present study should be interpreted in light of study being single centre, cross- sectional study with convenience sampling. Also, we have not examined social, cultural and other factors that are important in shaping attitude and stigma in general towards persons with mental illness, psychiatry and psychiatrists as well. We solely relied on self-reported attendance by students, which could not be verified from actual records.

\section{REFERENCES}

1. Bhise MC, Marwale AV, Deshmukh AS, Saoji SG. Impact of differences in psychiatry curriculum of undergraduate medical and physiotherapy students on their attitude towards psychiatry. Indian J Psychiatry 2016;58:208-11.

2. Pailhez G, Bulbena A, Coll J, Ros S, Balon R. Attitudes and views on psychiatry: A comparison between Spanish and U.S. medical students. Acad Psychiatry 2005;29:82- 91.

3. Srivastava A. Attitude towards psychiatry among medical students. J Indian Med Assoc 2012;110:706- 9.

4. Chadda RK, Singh MM. Awareness about psychiatry in undergraduate medical students in Nepal. Indian J Psychiatry 1999;41:211- 6.

5. Tharyan P, John T, Tharyan A, Braganza D. Attitudes of 'tomorrow's doctors' towards psychiatry and mental illness. Natl Med J India 2001;14:355- 9.

6. Balhara YS, Mathur S. A comparative study of attitudes toward psychiatry among nursing students across successive training years. Indian J Psychol Med 2013;35:159- 66.

7. Medical Council of India. Competency based undergraduate curriculum for the Indian medical graduate. Available from:https://www.mciindia.org/CMS/wp-content/uploads/2019/01/UG-Curriculum-Vol-II.pdf

8. Jacob KS. Medical Council of India's New Competency-based curriculum for medical graduates: A critical appraisal. Indian J Psychol Med 2019;41:203-9

9. Burra P, Kalin R, Leichner P, Waldron JJ, Handforth JR, Jarrett FJ, et al. The ATP 30- a scale for measuring medical students' attitudes to psychiatry. Med Educ 1982;16:31- 8.

10. Shaw ME, Wright JM. Scales for the Measurement of Attitude. New York: McGraw- Hill; 1967.

11. Adhikari SR. Medical students' attitude towards Psychiatry and Mental Disorders. J Psychiatrists' Association of Nepal 2017;6(1):18-23.

12. Hailesilassie H, Kerebih H, Negash A, Girma E, Siebeck M, Tesfaye M. Attitude of Medical Students towards Psychiatry: The case of Jimma University, Southwest Ethiopia. J Health Sci 2017;27(3):207-14.

13. Gulati $P$, Das $S$, Chavan BS. Impact of psychiatry training on attitude of medical students toward mental illness and psychiatry. Indian J Psychiatry 2014;56:271- 7.

14. Lingeswaran A. Psychiatric curriculum and its impact on the attitude of Indian undergraduate medical students and interns. Indian J Psychol Med 2010;32:119- 27.

$* * * * * * * * * * * * * * * * * * * * * * * * * * * * * * * * * * * *$

Acknowledgements - Nil

Conflict of Interest - Nil

Funding - Nil 